\title{
FICÇÃO E HISTÓRIA
}

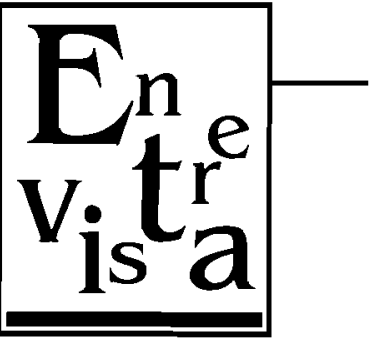

\section{NA TELENOVELA}

Nílton Travesso, dramaturgo e diretor do Núcleo de Teledramaturgia do SBT (Sistema Brasileiro de Televisão), relata sua experiência profissional e o atual desafio em consolidar um núcleo de produção para a TV na cidade de São Paulo

Energia é o que não falta a este dinâmico sonhador. São 42 anos de trabalho dedicados à TV brasileira. Pode até ser chamado de "patrimônio da telinha". E é com a maior naturalidade que ele conta os anos que passou à frente da $\mathbf{T V}$ Record, comandando a Equipe A, onde fez Família Trapo, Show do dia 7, Roquete Pinto e muitos outros programas. Saudoso, ele diz: "Foram tantas loucuras, aqueles incêndios no teatro Consolação, depois no teatro Paramount. A Record entrou numa fase difícil...".

Da Record foi para a TV Globo. Lá, como ele mesmo gosta de afirmar, "trabalhou a cabeça da Globo" para fundar um núcleo de TV em São Paulo. Aqui fez TV mulher, Balão mágico e Som Brasil. No Rio trabalhou com o Fantástico, Chico Anísio, novelas das seis, documentários. Foram 14 anos de batalha.

$\mathrm{Na}$ Manchete inovou a linguagem da telenovela com Pantanal e Ana Raio e Zé Trovão. Con- vidado para o SBT, encarou o desafio de fazer o público mudar o canal e sintonizar na novela de época.

Garra, profissionalismo e uma dose bem brasileira de criatividade foram ingredientes fundamentais na receita de Nílton Travesso durante as gravações de Éramos seis, as quais aconteceram quase simultaneamente à construção da cidade cenográfica na Via Anhangüera, em São Paulo.

Hoje, com o retorno favorável do público, Nílton prepara projetos para o futuro. As adaptações literárias de época continuam em seus planos. Sangue de meu sangue, novela de Vicente Sesso, cartaz da antiga TV Excelsior, e a adaptação de Dom Casmurro, obra de Machado de Assis, são seus próximos trabalhos. Confira todas as emoções da fala deste grande profissional nas páginas seguintes.

Por: Januária Cristina Alves ${ }^{1}$ 
Revista Comunicação e Educação - Como nasceu o projeto do núcleo de teledramaturgia do SBT, aqui em São Paulo?

Nílton Travesso - Primeiro, eu sou paulista, sou um dos fundadores da TV Record, que no dia 27 de setembro de 1953 foi pela primeira vez ao ar. Na Record eu fiquei praticamente 21 anos. Sou de São Paulo, minha vida toda é em São Paulo, e eu sempre batalhei muito por São Paulo. Na Record, nós fundamos a Equipe $\mathrm{A}$. Foi depois de um incêndio violento em um dos estúdios lá no Aeroporto. O Manuel Carlos, Raul Duarte, o Duda que hoje é dono da Jovem Pan, Mauro de Carvalho e eu lazíamos os programas da Hebe, Família Trapo, A noite se improvisa, Show do dia 7, Roquete Pinto; fazíamos praticamente uns oito programas por semana.

RCE - Essa sua equipe não fazia novela?

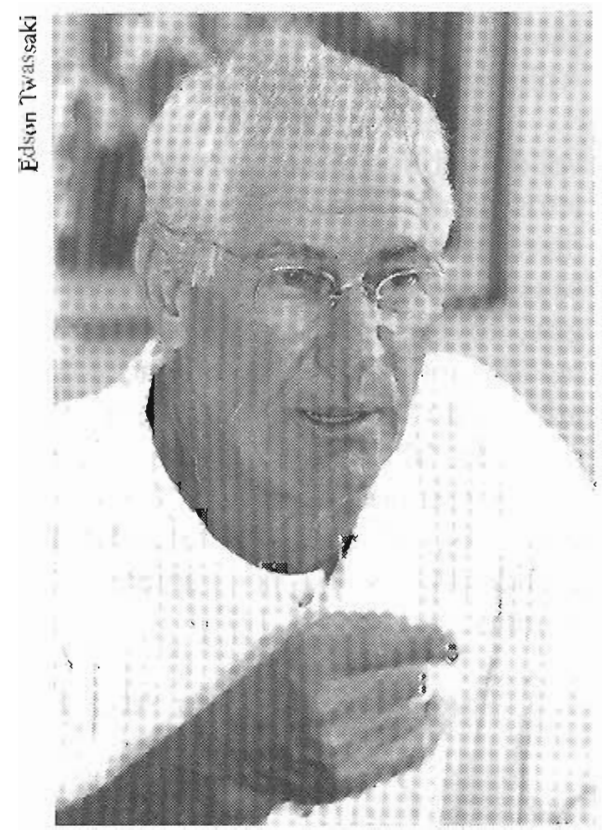

Travesso - Essa equipe não. Eu fiz teledramaturgia: novela e leatro. Durante dois anos fiz o teatro $\mathrm{Ca}$ cilda Becker, mas isso antes de eu ir para o teatro Record Consolação e fundar a Equipe A. Depois, a Record entrou numa fase muito difícil. Foram lantas loucuras, aqueles incêndios, no leatro Consolação, depois pegou no teattro Paramount. Toda aquela gama da Música Popular Brasileira: Chico, Caetano, Gil, Betânia, Gal, Elizete e Sílvio Monteiro foram se afastando, cada um foi cuidando da sua vida e eu também fui cuidar da minha. Fui convidado para fazer o primeiro Fantástico colorido na TV Globo. em 74. Eu fiquei lá uma temporada. Dentro da TV Globo batalhei muito pra montar um núcleo em São Paulo, que era a minha meta. Deu pra eu trabalhar a cabeça da TV Globo e acabei montando esse núcleo, em 1980. Aqui eu fiz o TV mulher, fiz o Balão mágico, o Som Brasil, que era com o Rolando Boldrin, e participei também da fundação do Globo rural. Montei o núcleo da linha de show do Fantástico pra fazer os clipes, batalhamos e trabalhamos nisso, mas o Boni insistiu e eu acabei voltando para o Rio de Janeiro, porque a Globo estava montando umas executivas. O Daniel Filho, que era um dos diretores, montou as executivas; o Roberto Talma, o Paulo Ubiratam e eu, cada um ficou com um núcleo de novelá, com um núcleo da linha de show e com os documentários. Eu fiquei com o horário da novela das seis, o Fantástico, o Chico Anísio e o Vídeo show. Então, eu tinha vários programas. A Globo estava distanciada da novela de época, mas eu aca- 
bei fazendo Sinhá moça e Direito de amar, que voltaram a capitalizar um bom índice de audiência.

\section{RCE - Elas estavam bem?}

Travesso - Muito melhor do que as novelas urbanas. Mas eu estava me deslocando do Rio de Janeiro. Acabei vindo para montar uma produtora independente que terminou não dando certo porque o Collor destruiu tudo. Fiquei na Manchete uma temporada, fui buscar o Jaime Monjardim, fizemos Kananga do Japão, Pantanal, Ana Raio e Zé Trovão. Depois a coisa foi diminuindo porque a administração era muito ruim e foi se perdendo. Saí da Manchete e aceitei o convite do Luciano pra vir para o SBT, para a teledramaturgia. Mas as decisões começaram a demorar muito porque o Sílvio estava traumatizado com tudo o que aconteceu em teledramaturgia, que não tinha dado certo.

RCE - Foi aquela novela Brasileiros e brasileiras, não é?

Travesso - Foi Cortina de vidro e depois Brasileiros e brasileiras e ele estava meio confuso. Foi um trabalho de quatro meses mais ou menos, até que o Sílvio concordou que a teledramaturgia é muito importante numa rede de televisão. Então nós fundamos a fábrica de novelas. Das três obras que eu tinha apresentado na nossa reunião de diretoria nós escolhemos fazer Éramos seis. Como uma novela de época, teria a vantagem de não brigar com a teledramaturgia da Globo, que tem uma tradição de 25 anos, e com quem ninguém estava a fim de competir. Nós estávamos a fim de abrir nosso espaço, criar um centro de produção em São Paulo e não de competir. Em nenhum momento passou pela nossa cabeça competir com a TV Globo. De qualquer jeito esse filão de novela de época estava aberto e Éramos seis é uma obra que já havia sido testada na televisão, já havia dado certo numa época e nós acabamos comprando a obra do Sílvio de Abreu e do Rubens Ewald Filho. Eu fiz um levantamento de produção e acabei montando a cidade cenográfica lá na Anhangüera. É um terreno do próprio Sílvio onde estão os escritórios comerciais e onde gravam o Hot-hothot. Tinha um espaço muito bom para os atores e a gente acabou montando lá. Mandei fazer um bonde no Rio de Janeiro, porque eu queria marcar bem o que era a Avenida Angélica e a Praça Buenos Aires. Começamos a trabalhar loucamente na novela com a promessa de que nós conseguiríamos dar dez pontos de audiência. Para o Sílvio dez pontos estava muito bom, para o comercial também. Acabou dando tudo certo e chegamos diariamente aos 17 pontos de audiência. No segundo horário chegamos aos $14,13,15$ pontos e para nós foi extremamente gratificante. Agora estamos partindo para a segunda novela, que também foge do urbanismo neurótico que a Globo faz genialmente bem. Nós estamos no caminho do romantismo, uma coisa mais singela. Esse tratamento tem continuidade na novela do Júlio Diniz, no romantismo rural dos camponeses do norte de Portugal. O Júlio Diniz foi um romancista português, de incrível talento, que morreu muito jovem, com apenas 32 anos de idade. Nós consegui- 
mos contabilizar e comprar essa obra que tinha sido adaptada pelo Lauro César Muniz. Estamos trabalhando em uma aldeia autêntica que fomos buscar em Sistela, que fica a $25 \mathrm{~km}$ da fronteira com a Espanha. Encontramos essa aldeia subindo ao Norte de Portugal, saindo do Porto e a escolhemos porque ela tem duas arquiteturas: uma é mais barroca e a outra é mais românica. E a história pede um tipo de aldeia românica que é toda de pedra. Isso nós só encontramos nessa cidadezinha chamada Sistela. Já gravamos as cenas iniciais, que se passam no Porto e em Guimarães. Estamos começando a gravar as locações, enquanto isso estão sendo construídos os estúdios e a cidade cenográfica. É um negócio meio trabalhoso, meio difícil porque nós no SBT partimos do zero. A gente ainda é muito jovem. A Globo tem 25 anos de tradição e estrutura. Mas graças a Deus está dando certo, o público está aceitando muito bem o nosso trabalho. É um trabalho que não tem prepotência nenhuma, pelo contrário, ele é feito com muito carinho, muito amor, inclusive pelo elenco, que é um elenco lindíssimo.

RCE - Muita gente da Globo, não é? Como é que foi trazer esse pessoal pra cá, foi muito difícil montar esse elenco?

Travesso - Não. Eu tenho muita amizade com essa gente. São 41 anos de vida, de trabalho por detrás. E convivendo com toda essa gente, fazendo dramaturgia, show, Fantástico, tudo isso abriu grande espaço. A Irene Ravache trabalhou comigo no TV mulher. Então tudo isso ajuda muito: companheirismo, trabalho, honestidade, seriedade.

RCE - Você está conseguindo fazer o pessoal se mudar?

Travesso - É, tem uma parte que teve que mudar para o Rio e agora está voltando. Elias Gleiser é o tipo do ator que sempre foi de São Paulo, trabalhou no teatro do SESI toda a vida dele. Mas a teledramaturgia era no Rio de Janeiro, então ele não tinha saída, tinha que morar no Rio. Todos eles estão voltando, Arutim, Elias Gleiser e a Débora mudaram para São Paulo.

RCE - A Débora Bloch, não é? Ela é que é a protagonista das $\mathbf{P u -}$ pilas?

Travesso - É. Ela faz a Guida, um papel muito forte. E o Juca de Oliveira que é paulistão, e tem fazenda aqui em Atibaia. Tudo isso ajuda: não só a amizade, o carinho e a forma profissional de trabalharmos, como também o fato de eles retornarem à casa deles. E para nós esse mercado de trabalho é muito importante.

RCE - Você acredita que, com essa fábrica de novelas, abre-se uma nova página na história das telenovelas no Brasil?

Travesso - Eu acredito que sim. Este lugar estava vago desde a Tupi e a Excelsior. São mais de 25 anos que em São Paulo não se formava um núcleo de produção. Ou era através de produtora ou sempre tinha alguma coisa que não dava certo. Acredito que agora dê. $\mathrm{O}$ futuro é muito difícil.

É uma empresa que vive de audiência. É uma estrutura toda marcada pelos números. A gente preci- 
sa ter muito cuidado e trabalhar para conseguir esse retorno.

RCE - O seu público é o mesmo das novelas da Globo, você tem isso medido? Quem é que vê?

Travesso - Não tenho isso medido, não tenho idéia. De qualquer jeito, a gente arma uma opção de horário para quem gosta de novela. A gente não bate de frente, em nenhum momento, com a Globo. Mas nós temos um público muito bom, por incrível que pareça, na faixa dos 9 a 12 anos e de homens dos 40 a 50 anos.

RCE - E você arrisca dizer o por $q u \hat{e}$ ?

Travesso - Não sei, quem sabe porque marca muito a história de São Paulo. Éramos seis relembra momentos incríveis da nossa cidade, como a Revolução de 32 . Tudo isso pode ter sido um grande capital para que esse público ficasse com a gente. E As Pupilas também têm esse tratamento histórico. É muito bonito você resgatar parte da história e trabalhar com grandes romancistas como a Maria José Dupré e o Júlio Diniz. A próxima obra que a gente vai fazer é do Vicente Sesso, que foi uma grande novela no tempo da Excelsior: Sangue do meu sangue.

\section{RCE - $O$ autor é brasileiro?}

Travesso - É, o autor é brasileiro. E depois a gente está trabalhando em cima do Machado de Assis com Dom Casmurro.

RCE - Essa vai ser difícil... Nunca foi telenovela, não é?

Travesso - Não, nem novela, nem minissérie, nada.
RCE - E quem vai roteirizar?

Travesso - Devem ser a Jandira e o Marcos Caruso. Porque a Jandira é uma estudiosa de Machado de Assis, e isso ajuda bastante no trabalho.

RCE - Você teve alguma preocupação didática na hora em que você pensou em adaptar esses clássicos ou foi, como você falou, para não concorrer com o filão da Globo, que é mais contemporâneo, urbano?

Travesso - Por incrível que pareça sempre essas coisas dão certo. Todas as obras que fiz, de grandes romancistas, grandes escritores, grandes autores sempre deram certo. E olha que eu não sou um otimista. É bonito você resgatar a época, o romantismo, eu acho super gratificante.

RCE - É interessante você estar falando isto, porque se diz que o brasileiro não gosta de ler, se lê, quando muito é para fazer vestibular. E é engraçado que, quando vai para a televisão, você estava dizendo que sempre dá certo. Como é que você vê isto?

Travesso - Eu acho que é porque retrata uma época muito bonita, uma época em que as pessoas às vezes até gostariam de ter vivido. Historicamente, você lendo ou contando ou estando numa sala de aula, é uma coisa, e você tendo toda uma produção por detrás, com locações, é outra. Sabe, você trabalha em cima do que foi realmente a época, desde o figurino, as locações, a estrutura de uma cidade cenográfica e até dentro do estúdio. Você trabalha com objetos de arte e toda essa estrutura, você tem uma ilustração muito bonita. É a mesma coisa que eu estar conversando no vídeo com você: se eu falar muito 
tempo, acabo cansando, mas se eu começar a ilustrar tudo o que eu estou falando na televisão, cria uma dinâmica muito mais bonita. As pessoas me aceitam de uma forma diferente. Então, o mesmo acontece com essas obras, às vezes elas são "cacetes" pra ler, pra estudar, pra debater. Mas a hora que você dá uma retaguarda visual pra ela até Robin Hood fica genial. Mas ler o Robin Hood é meio chatinho, já fizeram umas cinco versões. Então, por que eles fazem tão bem? Porque eles dão esse tratamento e vão atualizando. A mesma coisa nós estamos fazendo com Éramos seis, atualizando, trazendo pra cá com muito mais recurso, com muito mais visual, com muito mais tratamento, o que a primeira versão não teve. $\mathrm{Na}$ época não existia a cidade cenográfica, toda essa estrutura que nós temos hoje.

RCE - Originalmente Éramos seis é de que ano? Era Tupi, não é?

Travesso - Era, era Tupi. Tinha Nicete Bruno. Acho que foi em 69 , por aí, 68,67 .

RCE - Como é que você vê esse movimento da televisão de estar fazendo tanto remake? A Globo reapresentou Mulheres de areia, $A$ viagem, agora Irmãos Coragem, $o$ que que é isso?

Travesso - O Sonho meu já era remake! Era a junção de duas novelas de Teixeira Filho: A pequena órfã e Ídolo de pano.

RCE - Agora é Irmãos Coragem... Travesso - Dias Gomes readaptou. Foi uma das maiores obras da Janete Clair. Irmãos Coragem é de arrasar! Gostaria de poder fazer.
RCE - Mas como é que você vê isto, não tem bons autores de novelas, não tem bons roteiristas, por que isto acontece?

Travesso - Acaba ficando mais seguro num país com tamanha inflação, embora agora com o Real a coisa parece que está melhorando. Mas esta é uma maneira de você projetar a sua produção e saber quanto vai gastar, como é que vai trabalhar. Porque você tem idéia da obra total. Tem garantia do que vai fazer, pode planejar melhor. E trabalha com elenco fechado. Porque nas novelas "abertas" às vezes você entra com um ator, daqui a um pouquinho o autor muda, já não quer mais aquele ator. Você fica com o ator contratado, ele fica ganhando. Outros, que estavam indo embora, eu sou obrigado a renovar. Então, tem toda uma estrutura muito confusa quando você trabalha com a obra aberta. Trabalhando com a obra fechada, fica mais fácil. Tanto que foram reescritos 25 capítulos das Pupilas. Porque na época não existia cidade cenográfica, não tinha estrutura para ir ao Porto gravar as primeiras cenas. $O$ baile não teve a estrutura que demos a ele. Alugamos o Teatro Municipal para fazer o baile, contratamos mais de 200 figurantes. Isto porque você sabe o que está fazendo, e o que vai fazer, e como vai chegar ao final. Então, isso traz uma ajuda muito grande para a produção e para o planejamento de um trabalho tão grande.

RCE - De acordo com sua experiência, que temas dão mais certo em novela?

Travesso - Eu acho que essas novelas que a Globo faz, tipo as do 
Gilberto Braga, bem atual, vivenciando o social e o político, dão certo porque eles fazem isso muito bem e têm grandes autores. Ou seja, $90 \%$ dos autores brasileiros estão na Globo: Dias Gomes, Gilberto Braga, Benedito Rui Barbosa e Valter Negrão. Tanto que para trabalhar é um sufoco. Mas ao mesmo tempo a gente também está conseguindo trabalhar com um pessoal muito bom.

RCE - Você tem projetos de fazer um núcleo de autores e de roteiristas?

Travesso - Estamos trabalhando nisso. Tanto com autores como com atores e atrizes. A Ana Paula Arozio é contratada nossa, fizemos uma experiência com ela e ela já está fazendo um curso de teatro com o Humberto Silveira e vai fazer um curso de canto.

RCE - Há uma política de investimento em recursos humanos, então? Travesso - Tem várias pessoas nas quais estamos investindo, trabalhando e financiando inclusive cursos. Tudo para garantir o futuro.

RCE - Você acha, então, que essas novelas urbanas dão certo?

Travesso - Nem sempre. Precisa saber que tratamento se vai dar. Porque as pessoas estão cansadas, chegam em casa e encontram o mesmo problema, não é brinquedo! Mas é que a Globo é muito forte e ela, dando certo ou não dando certo, sempre aumenta a audiência. Eles bancam e dá tudo certo, não tem erro. Trabalhei lá 14 anos, conheço bem aquilo.

RCE - Você dirige todas as suas novelas?
Travesso - Eu começo. Nas Pupilas eu fiz a parte do Porto; em Éramos seis, todo o começo. Nós montamos uma equipe com o Henrique Martins, que é um grande diretor de elenco, e o Del Rangel, que é um excelente diretor. O Del tem feito coisas maravilhosas, a passeata que ele gravou foi lindíssima, foi cinematográfica. Eu começo, os dois vêm e eu parto pra próxima. Assim eles descansam para eu, depois, poder descansar também.

RCE - E o que é mais difícil pra você na hora de fazer uma novela? Travesso - É toda uma arquitetura complicada e uma das coisas mais difíceis é montar elenco.

\section{RCE - Por quê?}

Travesso - Porque uma novela sem elenco não acontece. Éramos seis tem momentos em que o texto não é assim maravilhoso. Lendo, você diz: "Nossa, que fraquinho!". Mas na hora em que uma Denise Fraga, uma Irene Ravache, um Otton Bastos, um Osmar Prado pegam aquilo, eles dizem aquilo com tanta força, que acaba ficando lindíssimo. Então, não existe novela sem um grande elenco e formar elenco hoje é difícil. Primeiro porque a Globo segura por dois ou três anos. Ela tem uma estrutura industrial e nós estamos começando. Temos que ir devagar, com o pé no chão. Nós já estamos formando nosso elenco. Beth Coelho e Denise Fraga são contratadas nossas. Elas descansam a próxima novela, vêm para fazer a outra. O mais difícil, portanto, é fechar elenco. Um elenco que já seja exatamente o perfil dos personagens, do que o autor imaginou e do que a gente também 
imagina quando adapta para dirigir. O complexo lodo também não é fácil, porque tem cenógrafo, tem diretor de arte, tem figurinista, tem maquiagem, e de época, então, é muito mais difícil.

RCE - Com quantas pessoas vacê está trabalhando atualmente?

Travesso - Aqui hoje nós devemos estar com umas 230 pcssoas.

RCE - E o custo disso, Nilton? Travesso - Essa novela sai um pouco mais barato, porque a cidade cenográfica, a estrutura dela, já está pronta. Nós vamos entrar em cima e trabalhar com casca em torno dela. Nas Pupilas o custo ficou bem menor, não mais que $28 \mathrm{mil}$ dólares por capítulo.

RCE - E a Globo gasta quanto por capítulo? É bem mais que isso?

Travesso - De 35 a 40 mil. Mas nós gastamos $32 \mathrm{mil}$ dólares por capítulo em Éramos seis.

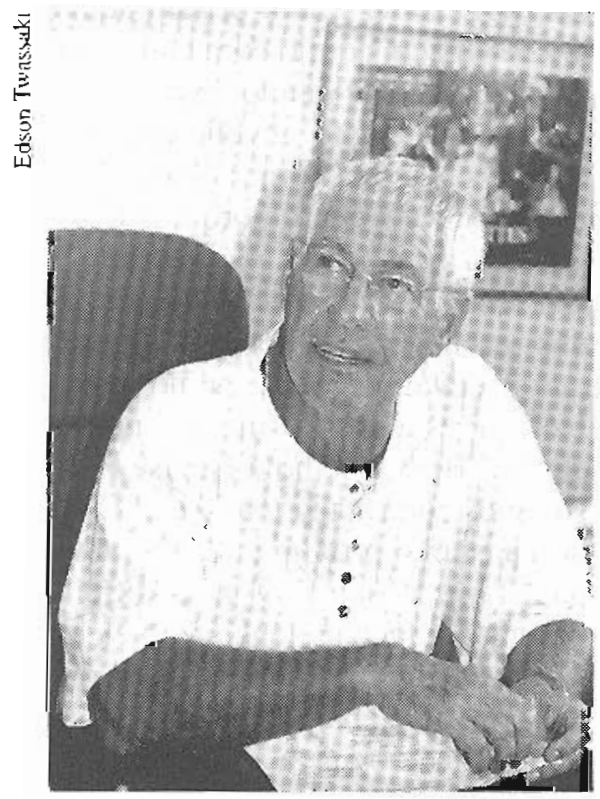

RCE - O que representou esse custo para vocês?

Thavesso - Bastante. Felizmente já estava patrocinada quando começou. A Gessy Lever acreditou no projeto e tivemos crédito do lado comercial do próprio SBT. O Sílvio Santos, o Luciano e todo o pessoal acabou acreditando que dava para fazer um bom trabalho e assim se abriu um belo mercado.

RCE - Eles interferiam em alguma medida no seu trabalho?

Travesso - Não.

RCE - O que você achou de o Sílvio bancar os dois horários?

Travesso - No começo eu estra nhei muito porque eu nunca tinha feito isso, achei uma loucura. Hoje é gratificante porque dá audiência nos dois horários e deve dar um retorno comercial também.

RCE - São duas frentes de teles. pectadores diferentes? Ou há pessous que assistem duas vezes ao mesmo capítulo?

Travesso - Muita gente assiste aos dois capítulos. Eu acho uma barbaridade, mas é um número muito grande. Ainda hoje el estava conversando e uma pessoa alé graduada me disse: "minha tia assiste duas vezes, não quer nem saber. Numa ela assiste à parte emocional e na outra ela quer ver os detalhes, quer ver como as coisas acontecem".

RCE - E As Pupilas permanecem nos dois horários?

Travesso - Permanecem.

RCE - Há certa vantagem nisso porque a emissora garante os dois horários com a mesma produção e com o mesmo custo, não é? 
Travesso - É e vai solidificando o espaço em teledramaturgia. O dia em que tivermos fôlego e recebermos um sinal verde, a gente produz duas novelas. Aí são duas novelas e se abre mais um campo de trabalho. Dobra tudo: dois diretores, dois assistentes, dois diretores de arte...

RCE - Você tem retorno das escolas, como é que o pessoal da área educacional tem se manifestado?

Travesso - Na parte de arquitetura é muito grande. $O$ pessoal que vai à cidade cenográfica quer ver como ela foi feita, como foi montada a sua estrutura. Há solicitações de pessoas da terceira idade. Durante as gravações de Éramos Seis eles queriam ver como era a Avenida Angélica. Lá, sábado e domingo é uma festa.

\section{RCE - A Revolução Constitucio-} nalista de 32, por exemplo, é um assunto que a escola não trata com a devida importância. Você acha que Éramos seis contribuiu para um maior esclarecimento sobre esse fato histórico?

Travesso - Tem gente que só entendeu agora o porquê do MMDC, as iniciais dos quatro heróis mortos durante o movimento revolucionário. Entenderam porque o Carlos foi morto e não foi o quinto. É que historicamente ele não estava fazendo parte do movimento, ele estava de passagem e levou um tiro. Foi um acidente. Por isso, ele não foi um herói, não podia ter deixado a marca de seu nome na história. Cada um dos quatro do MMDC que ia morrendo, a gente colocava o nome, a data de nascimento e morte, quase como um documentário.
RCE - Vocês tiveram preocupação em resgatar esses fatos com rigor histórico?

Travesso - Tudo certinho, acompanhando historicamente o que aconteceu, e com um historiador do lado. Tudo foi feito para que a gente não desse nenhuma informação errada. Nas Pupilas, nossa preocupação também foi grande, fomos até o Porto e tentamos recuperar todas as informações necessárias para a reconstrução da época.

RCE - Você acha que o público consegue perceber esse tipo de rigor?

Travesso - Olha, se não percebesse, nós nem estaríamos com essa audiência. Acho que a audiência e esse reconhecimento existem porque as pessoas sentem que nós estamos trabalhando seriamente. A única coisa é que nós vamos falar o nosso português, é claro. Não vamos sacrificar a língua. Mas a parte histórica é todinha trabalhada. Ficamos dois dias no Porto, subindo todo o Minho pra pesquisar a verdade do norte de Portugal, para ser fiel o mais possível.

RCE - Nílton, na sua opinião, qual é a função da novela?

Travesso - A novela faz parte, no Brasil, da nossa cultura, da civilização, do companheirismo e acabou sendo, durante todos esses anos, quase uma marca. Quando termina a novela, a audiência está no pico; quando começa outra, a audiência é baixa e depois devagarzinho vai subindo. Isto porque no decorrer da novela as mulheres se cansam e se sentem muito presas. Elas ficam estressadas, esgotadas e não querem mais saber de novela. Depois ela sai um dia, vai 
bater papo com uma amiga: "Você está assistindo, olha fulano de tal está bárbaro, a novela está linda...". E devagarzinho elas vão voltando e acabam sendo autoras por 24 horas todos os dias. Elas imaginam como a história tem que continuar, o que tem que acontecer. Então elas também são autoras, embora algumas vezes não dê certo o que imaginam.

RCE - A maioria do público são mulheres?

Travesso - A maioria.

RCE - Muito mais mulher do que homem e criança?

Travesso - Muito mais. Mas isso faz parte da nossa cultura, da nossa estratégia social.

RCE - E a função da novela é mais entreter do que ensinar? Você acha que a novela muda o comportamento das pessoas, que influencia? Travesso - Ao invés de a pessoa ir ao cinema, ela assiste à novela, que tem continuidade no dia seguinte. Porque a própria Globo hoje impôs um padrão muito bom, mundialmente não tem quem faça igual. É perfeito, o trabalho todo. Se você fizer uma análise, a gente faz dois filmes por dia aqui. Se pegar todas as novelas que estão no ar, são dois filmes por dia. Não há no mundo quem consiga fazer isso.

RCE - Recorde de produção e qualidade?

Travesso - Com qualidade e fotografia. Não é fácil!

RCE - Mas você acha que de alguma forma isso influencia o comportamento nacional?
Travesso - Influencia até em Portugal. Eu estava tentando passar a bagagem, que nós estávamos com 260,270 quilos de excesso. Quando a gente começou a conversar: "estamos com excesso e tal..., está meio complicado". Disseram "então vamos ter que fazer aquele pequeno cambalacho. Como brasileiro adora cambalacho!". Então, em Portugal, tudo o que se fala em novela eles sabem. E isso às vezes é bom e às vezes é até negativo, porque muda um pouquinho o itinerário da educação, da expressão, às vezes pode ser até perigoso.

RCE - Em termos educacionais, você acredita que a novela contribui em alguma coisa?

Travesso - Tenho certeza que nosso trabalho está contribuindo para que a pessoa tenha entretenimento e ao mesmo tempo tenha uns momentos de informação, de história. Até as Pupilas têm um pouco disso, sabe, de sentimento, de amor, de ciúmes, de educação, um embasamento muito romântico do Júlio Diniz. A pessoa fica a par do comportamento de uma época. Serve até para comparação, para ver como é que estamos hoje, o que é que acontece hoje e o que acontecia na época.

RCE - Esta é uma preocupação que você pretende manter? Vai trabalhar sempre nesta linha?

Travesso - A gente está segurando, a gente está trabalhando. Devagarzinho, porque também você não pode ser tão didático que aí as pessoas se desligam, não é? Você tem que ser en passant. As pessoas nem podem perceber que a gente está dando um tratamento didático em determinados momentos. Mas é esse o nosso caminho. 